\title{
Experimentar la deconstrucción de Jacques Derrida en la formación inicial del profesorado de artes
}

\author{
María Rosario García-Huidobro Munita \\ Departamento de Humanidades y Arte, Universidad de Los Lagos \\ rosario.garcia-huidobro@ulagos.cl \\ Artículo bajo licencia Creative Commons \\ Atribución 4.0 Internacional (CC BY 4.0) \\ ENVIADO: 2019-05-31 \\ ACEPTADO: 2019-11-25
}

\section{RESUMEN}

El artículo se centra en la experiencia del curso “Dibujo Deconstructivo”, desarrollado en la Universidad de Los Lagos, la cual fue presentada en el VII Congreso Internacional de Educación y Aprendizaje, Université Paris Dider, en Paris durante el 18,19 y 20 de julio de 2018.

El objetivo del curso buscó replantear nociones tradicionales del dibujo, a partir del pensamiento de Jacques Derrida, para alentar a los futuros(as) profesores(as) a experimentar diversas prácticas que cuestionaran el uso del dibujo técnico en la representación y fijación de la realidad. Para esto se discute la experiencia del curso a través de dos nociones fundamentales aprendidas; (1) el proceso reflexivo en la construcción del dibujo y (2) la implicación del cuerpo en esta práctica. Concluimos sobre la importancia de estos aprendizajes en la formación inicial docente para promover la subjetividad.

\section{PALABRAS CLAVES}

formación de profesores, proceso de aprendizaje, dibujo, pensamiento crítico, clase experimental.

\section{RESUMO}

0 artigo tem como foco a experiência do curso "Desenho Deconstrutivo", desenvolvido na Universidade de Los Lagos, que foi apresentado no VII Congresso Internacional de Educação e Aprendizagem, Université Paris Dider, em Paris, durante os dias 18, 19 e 20 de julho, 2018.

O objetivo do curso buscou repensar as noções tradicionais de desenho, com base no pensamento de Jacques Derrida, para incentivar futuros professores a vivenciar diversas práticas que questionassem o uso do desenho técnico na representação e fixação da realidade. É por isso que a experiência do curso é discutida através de duas noções fundamentais aprendidas; (1) o processo reflexivo na construção do desenho e (2) o envolvimento do corpo nessa prática. Concluímos sobre a importância dessas aprendizagens na formação inicial de professores para promover a subjetividade

\section{PALAVRAS-CHAVE}

formação de professores, processo de aprendizagens, desenho, pensamento crítico, classe experimental

\section{ABSTRACT}

The article focuses on the experience of the course "Deconstructive Drawing", developed at the University of Los Lagos, which was presented at the VII International Congress of Education and Learning, Université Paris Dider, in Paris during July 18, 19 and 20, 2018. The aim of the course was to rethink traditional notions of drawing, from the thought of Jacques Derrida, to encourage future teachers to experiment with different practices that question the use of technical drawing in the representation and fixation of reality. For this the experience of the course is discussed through two fundamental notions learned; (1) the reflective process in the construction of the drawing and (2) the involvement of the body in this practice. We conclude on the importance of these learnings in the initial teacher training to promote subjectivity

KEYWORDS

teacher training, learning process, drawing, critical thinking, experimental class. 


\section{INTRODUCCIÓN}

Para las carreras de Licenciatura en Artes, Bellas Artes y Pedagogía en Artes, los cursos de dibujo constituyen asignaturas disciplinares y obligatorias en las mallas curriculares durante los primeros años de formación, ya que su aprendizaje es considerado como base para que el(la) futuro artista y/o profesor(a) desarrolle las habilidades técnicas necesarias para desarrollarse en el área y en la creación de obra. En general, dependiendo del nivel de complejidad del semestre que cursa el alumnado, en estos cursos se aprende sobre estructura, composición de los elementos en el espacio, perspectiva, bodegón y figura humana, a partir de técnicas tonales, lineales, punteado, textura y tramado, ligado a un vínculo con lo real.

Esto significa que, en estas asignaturas, el dibujo es aprendido como una técnica o herramienta que reproduce la realidad, para que el alumnado adquiera las habilidades de interpretarla objetivamente sin cuestionarla. Esta lógica responde a situaciones políticas y sociales del siglo XIX, donde el arte $-\mathrm{y}$ así mismo el dibujo-, ha sido utilizado como medio para enseñar habilidades disciplinares y cognitivas que contestan a los procesos de industrialización del modernismo (Ossa, 2017). Como bien señala el profesor Ignacio Villegas, Este tipo de formación actual reproduce una visión cultural, en la que el dibujo ha seguido una línea tradicional respondiendo a patrones históricos.

El desarrollo de la noción de dibujo desde sus primeras actividades en tiempo de la Colonia hasta su plena instalación en el sistema educativo chileno, ha sido básicamente sostenido por la ya muy discutida polaridad: dibujo natural y dibujo lineal. El primero asociado a la representación verosímil del mundo y que toma como punto central de desarrollo la percepción visual y luego las emociones. El segundo, como depositario de la tradición matemática del siglo XVIII (Espinoza, 2017, p.39)

A partir de lo señalado podemos reconocer que el dibujo ha sido una disciplina mediada por aspectos políticos, económicos y culturales, los cuales han consagrado la necesidad de practicar su enseñanza - tanto en la formación de artistas como en la escuela-, para promover virtudes (la observación, la distinción, la medición de objetos y cuerpos) que ayudaran a desarrollar habilidades técnicas y manuales, y fomentarán una comprensión del mundo en tanto representación proporcional (Villegas, Navarrete, Camhi \& Espinoza, 2017).

Ante esta forma restringida de entender y aprender el dibujo, en este artículo se presenta la experiencia vivida en el curso "Dibujo Deconstructivo". Este fue un electivo de carácter práctico, que se dictó para los-as estudiantes de quinto y sexto semestre de la Carrera Pedagogía en Artes de la Universidad de Los Lagos, en el sur de Chile, durante el primer semestre de 2018. 
El principal objetivo de este curso fue promover la experimentación artística desde diversas prácticas que cuestionaran el uso del dibujo técnico y académico en la representación de la realidad objetiva y enseñaran nuevos acercamientos y experiencias sensibles hacia el dibujo. Se pensó relevante que los(as) estudiantes, además de aprender técnicas tradicionales del dibujo pudieran aprenderlo en su versión más experimental, introduciendo aspectos vinculados al cuerpo y el espacio. Para lograr dicho cometido, a lo largo del curso se promovieron diversos objetivos específicos, los cuales se desarrollaron como resultados de aprendizajes. (1) La reflexión grupal e individual sobre la utilización del dibujo como único método para reinterpretar la realidad, (2) explorar formas y materialidades del dibujo que den prioridad a la experiencia del cuerpo, (3) crear obra con un sustento teórico, compositivo y de materialidad que ponga en cuestión el dibujo tradicional y, por último, (4) discutir cómo estas nuevas experiencias artísticas entorno al dibujo deconstructivo son un aporte para la enseñanza de las artes en el aula escolar.

A partir de estos objetivos, centramos el aprendizaje del curso en la idea de la creación artística como experiencia (Derrida, 2005; Sullivan, 2010), pero sobre todo en una experiencia encarnada que involucra al cuerpo como campo de experimentación y que, por ende, transformaba a las clases y a la herramienta del dibujo en un espacio de experimentación crítica y dialógica que era transformativa. Sobre esto último profundizaremos más entrado el artículo, al desarrollar el proceso vivido a lo largo del curso y el compromiso del grupo con sus procesos de aprendizaje entorno a las artes.

A nivel epistemológico, centramos las bases introductorias del curso "Dibujo Deconstructivo" revisando la historia y la evolución del dibujo (Villegas et al., 2017), la exploración del cuerpo a través del arte (Warr, 2011; Cares, 2017), la performance y, sobre todo, el concepto de la deconstrucción (Derrida, 1997, $1998,2005)$ y sus aportes hacia el área de las artes. Con el grupo curso se analizó la noción de deconstrucción revisando diversos vídeos y textos (Derrida, 1998; 2005), para comprender desde qué perspectiva teórica y artística cuestionar las bases tradicionales del dibujo y lograr vincularlo con técnicas, movimientos y lenguajes contemporáneos que desafíen su uso tradicional y normativo en la historia del arte, permitiéndoles abrir la acción del dibujo hacia experiencias vinculadas con el cuerpo y sus subjetividades como artistas.

A partir de este bagaje teórico, el curso se desarrolló cada semana durante tres horas y, en cada sesión, se realizó un ejercicio práctico específico acorde a la unidad revisada. Las cuatro unidades que compusieron el curso fueron: (1) Dibujo, pensamiento y acción, (2) Dibujo y narrativa, (3) Dibujo, materialidad y cuerpo y, por último (4) Dibujo, comunidad y transformación, donde se desarrollaron ejercicios entorno al dibujo colectivo y orientados por la pregunta ¿cómo la experiencia de dibujar en comunidad puede promover cambios sociales y educativos? En el marco de cada unidad, cada semana se proponía un ejercicio práctico a ser resuelto en la hora de clase. Primero se exponía una problemática y se revisaba a diversos-as artistas que promovieran ese tipo de experimentación. A partir de esa introducción, el grupo debía individualmente explorar el dibujo, poniendo énfasis en el proceso de creación y no en el resultado. Para ello, cada uno-a debía registrar su proceso y, desde esa evidencia, dar cuenta de la experiencia vivida entorno a la creación. Las preguntas ¿cómo has vivido esta experiencia? y ¿cómo tu cuerpo se conecta con lo que estás dibujando-creando?, orien- taron el trabajo semanal. Al término de cada sesión se compartían los trabajos y sus reflexiones entre los-as participantes del curso. Esta instancia de socialización grupal permitía al grupo discutir sobre sus aprendizajes y la experiencia vivida. La evaluación del curso fue a través de portafolios, donde al término de cada unidad debían realizar una presentación digital de los trabajos y procesos explorados para cada ejercicio. El foco de las evaluaciones no estuvo en el resultado gráfico, sino en el registro del mismo y la capacidad de reflexionar en torno a este.

A partir de esta descripción del curso creemos relevante compartir con mayor profundidad cuáles fueron los mayores alcances y resultados del electivo propuesto, destacando cómo la experimentación en torno al dibujo permitió reflexionar sobre la experiencia de dibujar, centrados en el proceso. A su vez, resaltaremos cómo el curso llevó a un aprender de la acción artística para ser cuerpo artístico y transformar ese hacer en una apuesta política que promueve subjetividad en la formación inicial de profesores de artes. Para ello, a continuación, explicamos los aspectos más relevantes que se tomaron del concepto "deconstrucción” y cómo se vincularon con las artes visuales contemporáneas para ser enseñadas en el presente curso. Luego, nos centraremos en discutir los aprendizajes más relevantes del curso, los cuales serán ejemplificados con algunos ejercicios desarrollados en clases. 


\section{FUNDAMENTOS DEL CURSO: LA DECONSTRUCCIÓN Y SU VÍNCULO CON EL DIBUJO}

Bien es sabido que el término deconstrucción ha sido explorado por Jacques Derrida a partir del pensamiento de Heidegger y el trabajo que desarrolló éste sobre el concepto destrucción. A partir de aquí, Derrida toma el término utilizado por Heidegger y busca darle un carácter de desmantelamiento, generando un diálogo entre la fenomenología, el estructuralismo, el psicoanálisis y, sobre todo, la lingüística.

A modo de contextualización, este pensador francés comienza a desarrollar su pensamiento sobre la deconstrucción con el libro “De la Gramatología” (1998), donde cuestiona la forma en que la racionalidad ha operado en Occidente, un supuesto que deviene desde los antiguos griegos y que hoy se reproduce en el cómo entendemos la realidad. Lo que este autor quiere evidenciar, a través de la relectura que genera sobre diversos filósofos clásicos, es la oposición que se ha generado de manera histórica entre el habla y la escritura, en la que el habla es privilegiado por sobre la escritura. Es desde esta mirada que la deconstrucción que propone Derrida consiste en mostrar cómo la naturaleza de la escritura es vitalmente necesaria para el funcionamiento del habla, de esta manera realiza un llamado a abrir las fisuras que operan entre el lenguaje, la escritura y la realidad para descubrir los detalles, silencios e incongruencias que transitan entre estos. Desde esta invitación, Derrida va a desarticular la idea de un orden lineal, lógico y jerárquico de nuestra realidad, para mostrarnos que -finalmente- todo es relativo, paradójico y contradictorio, pues no es posible encontrar una verdad única en la realidad, sobre todo si pensamos desde el lenguaje; el habla y la escritura.

Por otro lado, en nuestra forma de comunicarnos con lo real y con los otros-as, hay un permanente diferir entre los términos que quieren significar una cosa y terminan significando otra. Por ello que deconstruir implica hacer un trabajo genealógico, analizando la historia de cómo un concepto o palabra, que pudo a lo largo de su historia ser de múltiples maneras, tiene finalmente un significado casi único. El lenguaje es entonces -según Derrida $(1997,1998)$ - un campo de batalla, al igual que el dibujo. ¿Por qué podríamos pensar esto y desde dónde podríamos hacer esta comparación? Porque el lenguaje es un campo de conceptos que quisieron significar una cosa, pero que cultural e históricamente terminaron siendo otras. Esta batalla presenta un conflicto de poder que transforma al lenguaje y al habla en un asunto político donde estamos condenados, puesto que no es posible escapar del lenguaje y acceder a lo real.

¿Cuál es nuestra relación con lo real? Esto es lo que Derrida nos señala y lleva a cuestionar con el término de la deconstrucción. Nos lleva a buscar las fisuras que hay en el lenguaje al intentar hablar lo que, por definición, está fuera del habla. Busca desmitificar los aspectos neutrales y objetivos del lenguaje para encararlos consigo mismos y permitir una otredad, lo que el también llama hospitalidad (Derrida, 2008). Esa otredad está vinculada con el hecho de que cuando ordenamos, según Derrida (1989) dejamos algo fuera y eso que apartamos es la diffèrance, otro concepto relevante de este autor. Esas diferencias, que son lo otro de lo otro, es lo que él nos llama a recuperar, explorar y visibilizar. A partir de aquí nos plantea que la deconstrucción es el proceso de abrir los textos a la relectura, para permitir diferencias, otras reinterpretaciones y nuevos significados con lo real. Es desestabilizar y problematizar lo que damos por sentado, la verdad única de las cosas, de las pala- bras y de la realidad, para visibilizar cómo aquellas ideas que se presentan como verdaderas o únicas tienen una trama, una historia, un conflicto y una incongruencia.

Ahora bien, ¿Qué ocurre cuando trasladamos este pensamiento de Derrida hacia el lenguaje visual y al cómo construimos el mundo desde las imágenes? es pertinente preguntarnos si acaso, ¿el dibujo describe la realidad tal cual la observamos y en qué medida refiere a las cosas? Si es el sujeto quien ordena la realidad desde el lenguaje, es factible también preguntarnos si somos nosotros quienes ordenamos, describimos e inmortalizamos la realidad desde el dibujo. Aquí es donde surge la pregunta derridiana; si acaso el dibujo puede ordenar, fijar e inmortalizar nuestra realidad.

Antes de responder este cuestionamiento creemos relevante realizar unas breves reflexiones en torno al dibujo y su carga histórica. Sabemos que el dibujo es una técnica, un lenguaje gráfico y medio de expresión que utilizamos para representar la realidad y también lo utilizamos para expresar aquello que no podemos describir solo con palabras (Ojeda, Bailón y García, 2014). Está presente en el ser humano desde sus inicios, pues los dibujos rupestres en las cuevas de Altamira son evidencias de esa imperante necesidad humana de representar e inmortalizar el mundo. Durante la Edad Media, el dibujo también se materializó en el desarrollo de pergaminos que narraban historias, desplazándose entre lo simbólico y lo real. A partir del Renacimiento comienza el estudio detallado del dibujo como método para reflejar la realidad. Con Filipo Brunelleschi surge el estudio de la perspectiva como técnica que representa fielmente el espacio real y con Leonardo da Vinci se utiliza al dibujo como un medio para conocer(nos) el cuerpo desde una lógica analítica.

La historia nos permite evidenciar cómo desde el Renacimiento el dibujo opera desde un modo matemático y racional, que objetiviza la realidad cosificándola. Sobre este pasaje histórico, cuenta Francastel (1990) que en esta época se busca el descubrimiento y desarrollo plástico de leyes que permitieran representar fielmente la realidad como una forma de conocimiento. A pesar de esta intención, "el objetivo del arte no es producir duplicados en dimensiones reducidas, sino fijar conductas e interpretaciones humanas" (Francastel, 1990, p.96).

En la Europa del siglo XIX se profesaba una estética conservadora que promovía el dibujo realista, temas históricos o alegóricos que consideraban que el gran arte era la imitación de la naturaleza. Esto que mencionamos no es menor, puesto que una de las actividades que mayor prestigio otorgaba a los-as artistas y los-as validaba como genios era su participación en las clases de dibujo al natural que se desarrollaban en las Academias de Bellas Artes europeas desde el siglo XVII (Nochlin, 1971).

A partir del Impresionismo, el dibujo como fijación de la realidad deja de ser la búsqueda principal de las artes, puesto que en esta época se exploró cómo el ojo, al desplazarse, muestra una realidad modificada e inacabada. La intención es sugerir un espacio a través de lo pictórico, más que definirlo a través del dibujo racional y, ante ello, se abandona el punto de vista tradicional propuesto por el Renacimiento para abrirse a una evocación de la realidad. Por otro lado, Cézanne cuestionó las convenciones de la representación y con la exploración del geometrismo clásico de los volúmenes, abrió paso a la idea del artista como un creador de objetos más que un representador, a partir de la pintura y el escorzo espacial de los objetos (Francastel, 1990). Con el Impresionismo, y luego con las 
Vanguardias, se cuestiona la tradición plástica y la posibilidad de una representación fija, puesto que "no se trata ya de fijar un punto de vista, sino de sugerir valores" (Francastel, 1990, p.190), interacciones e interpretaciones humanas.

Lo relevante que buscamos precisar a través de este recorrido histórico, es subrayar cómo el dibujo se instauró como una técnica que fija la realidad. Pensamos que a pesar de que esta técnica utilice signos o trazos que interpretan, o construyen un imaginario ficticio, históricamente se ha utilizado como una técnica que representa lo que ya está dado. Es aquí donde realizamos los vínculos con la deconstrucción. Si este término llama a desmantelar la realidad, a cuestionar lo dado para buscar múltiples interpretaciones, a un descentramiento de la verdad única y una apertura entre el signo y su significado, entonces la herramienta del dibujo padece la misma enfermedad que la escritura, puesto que ambos lenguajes fijan e inmortalizan una realidad de manera única; una mediante las palabras y la otra desde la representación gráfica.

¿Cuál sería el llamado según Derrida? Primero es comprender que el dibujo, por sus cualidades expresivas, no puede ser una técnica que fija la realidad de manera inmanente y única, porque no es real y no puede ser excluyente de otras realidades. Lo segundo sería valorar que al ser el dibujo una expresión del hombre, indudablemente conlleva una conexión con el cuerpo, característica que no ha sido considerado en esta técnica porque históricamente hemos vinculado al dibujo como una técnica que pone su atención analítica en algo que está fuera -objeto que se observa, paisaje que se admira, cuerpo que se estudia-, más que en el mismo sujeto creador que lo realiza. Hemos olvidado que el dibujo nace de la experiencia corpórea del ser humano, es una manifestación que se expresa como extensión de su cuerpo sobre otro soporte o medio y que no radica en lo que produce, sino en el cómo lo hace. Preguntarnos por el cómo ese(a) artista construye su creación conlleva poner el acento en el proceso, en eso que corporalmente ocurre al dibujar. Lo tercero, y ligado a lo anterior, es comprender que si el dibujo pasa por la expresión del cuerpo y lo que nos acontece al hacer este ejercicio, indudablemente el vínculo con lo real se desvanece, puesto que dibujar se transforma en una acción corporal que no interpreta realidades, sino experiencias de ser y hacer, mediante trazos imaginan, distorsionan o descentran la realidad. A partir de estas ideas, Derrida se pregunta:

"¿Qué es un trazo?», o "¿En qué se convierte un trazo?», o «¿Con qué se relaciona un tal trazo?». Sino «¿Cómo se trata el trazo? ¿Y se contrae en su retraso?». Un trazo nunca aparece, nunca por sí mismo, dado que marca la diferencia entre las formas o los contenidos del aparecer. Un trazo nunca aparece, nunca por sí mismo, nunca por primera vez. Comienza por retirarse. Sigo aquí la consecuencia de lo que había llamado hace mucho tiempo, antes de llegarle el turno a la pintura, la mella del origen: lo que se abre, de una traza, sin iniciar (Derrida, 2005, p. 25).

El juego lingüístico que propone Derrida nos lleva a prestar atención a la pulsión que vivimos al gestar y vivificar un trazo, a quién lo materializa y su historia. Es una práctica que se transforma en dialógica porque no se cierra a lo dado, sino que se abre a su devenir y a una reflexividad que involucre un pensar con. El llegar a ser dibujo es lo que Derrida (2004, p.175) llama "trayecto o las etapas de un «viaje»", y es esta práctica centrada en el cómo, en un trazo que se abre a lo irresoluto, e inconcluso, desafiando la normalidad de las artes y abriendo lugar a la experiencia nómada como eje central de esta práctica.
Derrida (2005), en su obra “La verdad en pintura”, analiza una serie de imágenes sobre las que concluye que el dibujo es igual a tr. Llega a esta idea al señalar que tr (o sea el dibujo) equivale a "trazo, trayecto, tramado" (p.180). Sin embargo, precisa que, "si tr resulta alterado en cada oportunidad, transformado, desplazado por lo que parece completarlo, guarda una suerte de suficiencia, no una identidad consigo, sentido o cuerpo propio, sino una extraña y altiva independencia" (p.180). Lo que este pensador intenta decirnos a través de su análisis, es que el dibujo es una práctica que implica trazar, generar trayectos, tramados, transformaciones y que, al igual que el lenguaje, no es posible cosificarlo como algo cerrado, sino más bien es un rizoma que se abre a su propio devenir del cuerpo.

Es desde esta perspectiva que el curso “Dibujo Deconstructivo" se ha situado, desarrollando diversos ejercicios que han puesto en cuestión nuestra relación con lo real. Al igual como Derrida nos propone encontrar las fisuras del lenguaje, este curso propone ejercicios donde el alumnado explore las fisuras del dibujo, trazando y experimentando lo que, por definición, históricamente ha estado fuera de esta técnica tradicional: (1) el proceso de construcción de un dibujo, (2) la implicación del cuerpo y (3) lo irresoluto en esta práctica. A partir de este diálogo con la obra de Derrida, en el próximo apartado profundizaremos el desarrollo de estas características en el curso, ejemplificándolas con dos ejercicios desarrollado por los-as estudiantes. 


\section{DISCUSIÓN DE EXPERIENCIAS EN TORNO AL DIBUJO DECONSTRUCTIVO: PERFORMANCE}

En la Carrera de Pedagogía en Artes de la Universidad de Los Lagos, los(as) estudiantes cursan tres cursos de dibujo de carácter obligatorio. En Dibujo I, se aprenden aspectos básicos sobre la forma y la jerarquización de los objetos geométricos en el plano bidimensional, atendiendo a su estructura, proporción, perspectiva y composición, para finalmente componer dibujos clásicos y analíticos, mediante las técnicas de achurado, valores de luz, media tinta y sombras. En Dibujo II, se complejizan lo aprendido en el curso anterior, profundizando en la construcción de bocetos y dibujos artísticos de figuras orgánicas y bodegones. Finalmente, en Dibujo III, se trabaja la figura humana al natural, su composición y proporción. Como se puede apreciar, dichos cursos se estructuran en base a la realidad y el tipo de dibujo que se aprende señala una representación real del mundo, lo que evidencia un enfoque de enseñanza que pone énfasis en el aprendizaje de las artes como academia (Raquimán \& Zamorano, 2017).

Analizando la construcción lineal de estas enseñanzas y para romper el encasillamiento del dibujo con la realidad, se desarrolló el curso optativo "Dibujo Deconstructivo", con el objetivo de promover un mayor cuestionamiento sobre esta práctica y fomentar que los(as) artistas en formación exploren otras formas no académicas de (des)dibujar, utilizando materialidades que rompan con lo tradicional y que, sobre todo, les permitiera implicar sus corporeidades tanto en el dibujo como en la experiencia de creación. Pensamos que desarrollar estas experimentaciones los y las posicionaría como artistas más abiertas ante la enseñanza, puesto que el foco no estaría en el resultado, sino en el proceso y el aprendizaje. Para llevar a cabo estas estrategias, el curso se dividió en cuatro unidades: (1) Pensamiento y acción, (2) Trazo y narrativa, (3) Materialidad y cuerpo y (4) Comunidad y transformación. En cada sesión se desarrolló un ejercicio práctico que aludía a dicha unidad.

Para reflexionar en torno a prácticas de enseñanza que disrumpen la relación con lo real, a continuación, nos centraremos en compartir y discutir dos aspectos relevantes que fueron aprendidos a lo largo del curso: la práctica del cuestionamiento, y el cuerpo como acciones que deconstruyen la práctica del dibujo tradicional.

\subsection{EL PROCESO DE CREACIÓN Y APRENDIZAJE ARTÍSTICO ES} UN CUESTIONAMIENTO

A lo largo del curso se pudo comprender que la experiencia de dibujar no podía ser una práctica libre de pensamiento, puesto que el proceso de creación requiere una consciencia reflexiva sobre lo que se construye, sin importar el tipo de experimentación artística. Sobre estas ideas, Donald Schön (1998) ha expresado que los(as) profesionales realizamos un tipo de reflexión que se genera desde y sobre las acciones que realizamos, pues, al mismo tiempo que realizamos una práctica se construye un saber que es fruto de dicha reflexividad activa. Es una reflexión de carácter crítica, ya que cuestiona la estabilidad de nuestro conocimiento en acción, para dar paso a la sorpresa, a lo no esperado y a nuevas formas de conocer y conocernos como profesionales. Schön (1998) llama a este acto de dar sentido a aquellas acciones de nuestra práctica, reflexionar sobre nuestro conocimiento en acción, lo que significa tomar conciencia sobre los eventos que nos van sucediendo cotidianamente, pero también los que nos han acontecido en la acción creativa.

En el caso de este curso, los(as) estudiantes pudieron reflexionar sobre los dibujos, gestos o trazos que fueron realizando, pero también a partir del mismo acto de trazar -en medio de la acción-como un diálogo que los(as) acompañaba en el hacer. A esto, Schön (1992) también lo ha llamado metafóricamente conversación reflexiva con los materiales de una situación. A medida que se va trazando se puede pensar en reorganizar y cuestionar lo que vamos haciendo. A través de esta reflexión en acción no solo se pueden hacer conscientes las direcciones del trazo o colores que se utilizan, sino que también cuáles son sus significados y relaciones, pues, ese proceso puede influir en el por qué hacemos lo que hacemos, abriendo nuevas posibilidades y significaciones que nos reposicionan como artistas.

Para ejemplificar cómo el cuestionamiento en la acción fue parte del aprendizaje deconstructivo de las artes, revisaremos el relato de una estudiante que, para el segundo ejercicio de la unidad "Trazo y narrativa", compartió una experiencia que para ella fue crucial en su proceso de creación, con respecto al cuestionamiento en las artes.

El ejercicio de dicha sesión consistió en desarrollar un autorretrato o retrato donde utilizaran un texto o relato como construcción simbólica de la imagen. El texto se podía emplear como forma creadora de la imagen, suscitador de ésta o bien como desarticulación metafórica.

La estudiante, a modo de registrar su proceso, dispuso un móvil sobre su espacio de trabajo para grabar el encargo a realizar. Como se aprecia en las imágenes (véase Figura 1), comenzó a crear su autorretrato con grafito, realizando un trazo que delineaba su rostro de manera realista. 

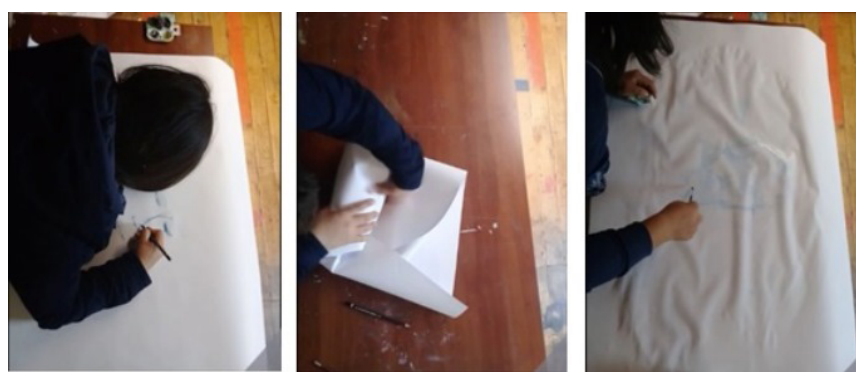

Figura 1. Estudiante de curso Dibujo Deconstructivo realizando trabajo sobre Unidad de Trazo y Narrativa.

Fotografía: María Rosario García

De pronto, el vídeo muestra cómo la estudiante detiene su acción, cambia de papel y comienza una nueva creación donde humedece la hoja con agua - dejando un charco-y, en vez de autorretratarse de modo realista, traza un ojo - que se diluye por la cantidad de agua-, por medio del cual comienza a buscarse a sí misma. El dibujo del ojo se esfuma y funde con el líquido y es, en ese reflejo del agua, donde ella busca y observa su retrato. La estudiante cuenta que, todo este trabajo, lo realiza repitiéndose a sí misma la frase "quién soy cuando me veo", siendo ese relato cuestionador quien gatilla y guía su acción para autorretratarse a través de la búsqueda de su reflejo. Al finalizar el ejercicio, cuando los-as participantes del curso comparten el trabajo, la estudiante mostró el vídeo a sus compañeros(as) y expresó:

"Al momento de relacionarnos con el retrato, inconscientemente pensamos en un lápiz, carboncillo u otro material comúnmente usados para este tipo de creaciones (...) Considero que el dibujo académico no siempre me ha gustado... lo rechazo, en momentos y creo que fue el primer de tonante para cambiar lo que hacía... me sentí incomoda, lo que hacía no reflejaba lo que quería hacer (...) Cambie de hoja después de sentir que ya estaba ocupada, recordé el agua y lo mucho que me gusta trabajar con ella... pensé en el autorretrato...en el reflejo... como me ven los demás ... como me veo yo ...y si eso es realmente lo que soy (...) entonces pensé en ¿qué se ve cuando se ve?... a partir de eso formé el ojo para buscarme... que es el reflejo de lo que soy. Solo reflejo." (Relato de la estudiante).

El vídeo y relato de la estudiante son esenciales para comprender el proceso deconstructivo del dibujo y las artes. Más allá de la producción final, consideramos relevante acoger el llamado de Derrida para preguntarnos en qué se convirtió el trazo de la estudiante y qué nos enseña el trayecto o viaje que experimentó para -ella- llegar a ser dibujo (Derrida, 2005). Es importante detenernos en la frase que expresa la estudiante: "qué se ve cuando se ve", la cual cuestiona y orienta su trabajo. Sobre esta idea, Judith Butler (2004) ha señalado que las palabras trascienden lo comunicativo porque pueden alterar la realidad. En este caso, dicha frase toma un papel detonador que potencia su actuar porque lo transforma. El cuestionamiento y la reflexividad que acompaña su acción nos enseña cómo performativizar nuevas formas y acciones creativas sobre el hacer artístico que cuestionan la tradicionalidad del arte; específicamente los modos convencionales de realizar el dibujo de un retrato o autorretrato.

Sobre estas ideas, María Acaso (2012) señala la importancia de asumir el papel performativo de las imágenes, es decir, cómo el lenguaje visual tiene el poder de transformar la representación en nuevas maneras de entender(nos) la realidad.
Este legado proviene de Charles Peirce (1839-1914), quien desarrolló la teoría del significante y el significado, generando grandes aportes a los estudios de la semiótica visual. Peirce (1988) cuenta que la semiótica pragmática es aquella que estudia los signos en relación con los sujetos y su contexto, visibilizando la necesidad de vinculación y cuestionamiento entre ambos. El signo es la representación de algo y el tipo de signo-metáfora sería - según Peirce- los puntos en común entre un ícono y su representación, pero desde un sistema de representación diferente; lo que apunta a la construcción de una nueva realidad. Algo no dado. Esta idea nos permite entender la existencia metafórica de algunos signos, donde más que ser descriptivos de una realidad son performativos (Acaso, 2012), puesto que en esta relación sujeto-contexto los signos no son estáticos, sino un medio que nos conforma y transforma.

Si vinculamos este pensamiento de la semiótica visual con los gestos que desarrolló la estudiante en su trabajo - disrumpir la acción de dibujarse representativamente para interpretarse desde su reflejo en el agua como una búsqueda-, podemos comprender los aportes del pensamiento deconstructivo. Es una invitación a cuestionar e irrumpir el propio pensamiento visual de la representación real para situarnos en un plano de construcción activa y corpórea. Según Peretti (1989, p.18), "Derrida se propone, ante todo, mostrar la imposibilidad, el error radical que supone toda voluntad ideal de sistema; rechaza cualquier tipo de centralidad, de fijeza”.

Llegar a ser dibujo (Derrida, 2005) se transforma en una potencia, en una búsqueda metafórica que trasciende el resultado visual para situarse en signos que crean una realidad artística inmanente y contingente. El signo de la estudiante -buscar en el agua su reflejo-, se convierte en una experiencia que transforma lo dado en un viaje y una búsqueda. A partir de ideas deconstructivas, el autorretrato se aleja de nociones tradicionales para centrarse en gestos metafóricos que llegan a ser desde la acción corpórea y efímera que se vinculan al cómo me pienso y cómo me siento. Cuando la acción artística acoge al cuestionamiento como motor y esencia, se reestructuran nuestras estrategias de acción y podemos corporeizar nuevas formas que rompen con lo ya dado para abrirnos a lo irresoluto de la experiencia artística (Atkinson, 2016). 
3.2 PERFORMANCE: EL CUERPO EN ACCIÓN CREA Y RECREA REALIDAD ARTÍSTICA

Revisando brevemente la historia, tras la II Guerra Mundial el arte dio un giro que marcó una nueva búsqueda ante los medios, espacios e ideologías que, hasta el momento, lideraban a las artes. Se comenzaron a explorar nuevos lenguajes para expresar acciones con sentido artístico que cuestionaron el papel del(la) artista como genio individual y a la obra como un resultado fijo y externo a él o ella. El cuerpo comenzó a ser explorado como lienzo, herramienta y un campo de acción que cuestionaba los estereotipos de raza, género y sexualidad, las relaciones con la tecnología y sus limitaciones para señalar su actuar como un tipo de conocimiento (Warr, 2011). Luego, a partir de los movimientos sociales de los 60', se intensificó la búsqueda del cuerpo para hacer experiencia artística y se manifestó como artes de acción (González-Victoria, 2011), performances y happenings con un alto compromiso político. En estas nuevas experiencias no solo se trabajó la veta carnal del cuerpo, sino sobre todo su potencial relacional, dando énfasis al cómo se materializan las relaciones y problematizando a los-as otros-as -espectadores-, como los agentes que activaban y significaban a la obra. Es en esta búsqueda donde toma lugar lo performativo, pues, el cuerpo se transforma en una forma de entenderse socialmente y un espacio de relaciones sociales.

Para vincular la idea de performance con la experiencia vivida en el curso de Dibujo deconstructivo, compartimos el primer ejercicio que se realizó en la I Unidad de "Trazo, pensamiento y acción". Para aquella sesión, el grupo debía realizar un trabajo donde su pensamiento liderara su accionar desde el trazo libre.

Reflexionaremos sobre el ejercicio que desarrolló un estudiante, quien decidió enfocarse en el movimiento que hacen las abejas cuando cogen el polen de las flores. Para registrar su acción artística y proceso, el estudiante dispuso la cámara de móvil sobre su espacio de trabajo (véase Figura 2), y a su alrededor dispuso tres hojas blancas, las cuales metafóricamente hacían de flor.
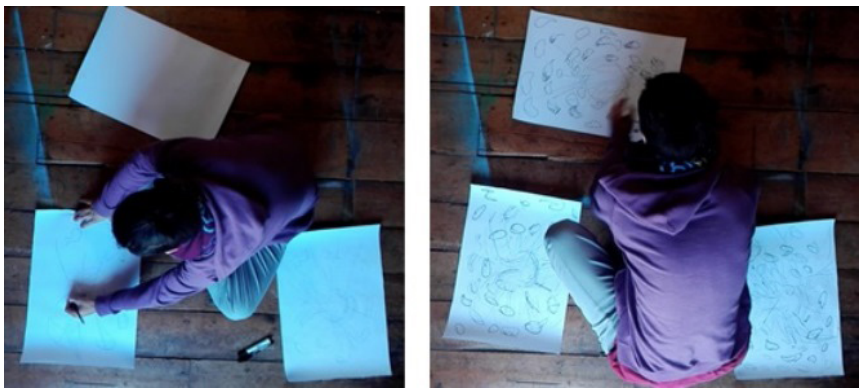

Figura 2. Estudiante de curso Dibujo Deconstructivo realizando trabajo sobre Unidad de Trazo, pensamiento y acción

Fotografía: María Rosario García

El trabajo del estudiante consistió en rayar las hojas interpretando el rápido y aleatorio movimiento que hacen las abejas al desplazarse de flor en flor. En dicha acción, el cuerpo del estudiante se transformó en una abeja que se desplazaba energéticamente entre las tres flores - hojas blancas-. Su objetivo fue visibilizar dichos desplazamientos mediante el trazo. El resultado del trabajo se materializó en tres hojas completamente rayadas de manera circular y aleatoria, que carecían de sentido si no comprendíamos la acción que le daba origen. Lo relevante no eran los dibujos, sino su accionar, cómo su cuerpo vivifica la experiencia de ser abeja y, en ese sentir, el trazo como una proyección del sentirse abeja.
En primer lugar, el ejercicio artístico que relatamos nos ayuda a entender cómo al desestabilizar la tradicionalidad del dibujo permitimos que el trazo cobre vida desde el deseo de ser y hacer. En este caso, el deseo de ser abeja transforma el movimiento del estudiante en trazo y no viceversa, puesto que es su autoría y agenciamiento, lo que disrumpe la tradicionalidad del dibujo. Estos giros y rupturas permiten modificar las epistemologías del hacer artístico, porque la creación no se funda en el resultado del dibujo, sino en la experiencia vivida del artista en formación. Es decir, el llegar a ser dibujo desde su acción como abeja. En este sentido, rescatamos la importancia de aprender a negociar sus subjetividades en la formación docente a través de estos ejercicios, porque en estas instancias emergen nuevos espacios de significación que desafían lo dado y se abren a lo nuevo (Atkinson, 2011). Esto, para Kenneth Gergen (1996), es el corazón del agenciamiento; una acción que al ser transformativa y novedosa permite que el saber de los y las estudiantes se vaya configurando desde esa misma realidad. Es una acción que permite abrir caminos para que emerja la subjetividad como fuente y trayecto de saber que resitúa sus propios procesos de aprendizaje.

En segundo lugar, este ejercicio nos permite entender qué ocurre cuando entregamos protagonismo al cuerpo, para que sea el gesto del desplazamiento quien trace. Son sus gestos corporales quienes activan el trazo. Por ende, del dibujo como objeto, donde el cuerpo yace cosificado, pasamos al acto mismo de trazar, en el cual la experiencia entorno al trazo resig. nifica la obra, puesto que no es solo lápiz y mano quien crea, sino todo su accionar. Aquí es cuando el dibujo - según Derrida (2005) - es tr: transformación, tránsito, trayecto y tramado. El cuerpo se activa, se abre como impulso a la creación y el dibujo deja de ser un resultado fijo y externo, sino que es esa inmaterialidad que crea travesías y redes.

Cuenta María Acaso (2012) que la performatividad en las artes explica cómo la representación visual pasa de ser estática y dada, a una transformación de la realidad. Ello, porque el poder transformativo de las imágenes y de su accionar conlleva cambios en la forma de percibirla, en cómo entendernos como artistas y, en este sentido, en el tipo de creación artística. Según Roland Barthes (2002), la pintura dejó de ser considerada una maestría del ojo cuando se comprendió la relevancia del cuerpo como creación. Siguiendo esta idea, el dibujo abandona su veta u objetivo disciplinar cuando se transforma en una proyección activa del cuerpo. Gómez-Peña (2005) señala que la performance es un lugar de colocación interno, que apunta a una búsqueda de libertad, donde el cuerpo como materia prima se transforma en ese sitio de creación, en ese lienzo en blanco y carta de navegación que proyecta deseo.

La performance entonces, se abre como un espacio de creación en el cual él o la artista abandona reglas y jerarquías no solo con otros(as), sino sobre todo aquellas vinculadas con la institucionalidad artística para reconfigurarse como artistas. Esta idea nos enseña cómo los y las artistas en formación, al incorporar aspectos performáticos en su aprendizaje del dibujo comienzan a experimentar nuevas vivencias en torno a esta práctica, puesto que cuestionan y se despojan de las normativas que institucionalizan el dibujo tradicional, para otorgarles otros sentidos desde sus subjetividades. Es aquí donde emerge lo que Merleau-Ponty (Bazzurro, 2015) ha llamado relación intercorporal o intercorporalidad, y es justamente cuando los cuerpos se implican para hacer desde un deseo de ser con otros-as. En relación a estas ideas, podemos señalar que experimentar la deconstrucción en la práctica del dibujo es un llamado a vivir 
el cuerpo, escuchar el llamado corporal para trazar esas relaciones de hacer y, de esta manera, transformarse en ser. Trazar las relaciones que vamos construyendo y significando son una acción performática que surge desde esa relación intercorporal -cuerpo físico y deseo-, donde nuestro cuerpo proyecta o traza los gestos que surgen desde nuestros deseos de ser algo o alguien: nuestra corporalidad.

\section{CONCLUSIONES. EL SENTIDO DECONSTRUCTIVO DEL ARTE EN LA FORMACIÓN INICIAL: CONSTRUYENDO SUBJETIVIDAD}

A modo de colofón, consideramos pertinente valorar los aportes que ha entregado la práctica de la deconstrucción en la formación de artistas-docentes, sobre todo los modos en que favorece la subjetividad. Este concepto refiere a los pensamientos, sentimientos y emociones que experimentamos en contextos sociales y discursivos, y los significados que vamos dando a esas realidades (Burke \& Jackson, 2007). En este sentido, este curso fue una instancia innovadora que abrió posibilidades para cuestionar sus formas de hacer y aprender el arte, pues permitió vincularse con el cuerpo, los deseos, emociones, aquello que nos afecta y mueve.

Desde esta lógica, el curso se desplegó como espacios donde iba emergiendo la subjetividad de los saberes del alumnado, pues, al cuestionar sus relaciones anteriores con el dibujo, surgían experiencias novedosas donde pensaban y practicaban el dibujo como un aprender a ser con lo otro (compañeros-as, deseos, cuerpos, materiales, historias previas). Esta idea nos permite reafirmar que, finalmente, el dibujo deconstructivo es un hacer que surge del deseo de relacionar el cuerpo, los gestos y un constante cuestionamiento, como elementos que están -en palabras de Karen Barad (2003) - intra-activos, es decir, vinculados entre sí. Apropiarnos de este concepto de Barad para el acto artístico nos permite entender cómo la práctica del dibujo contemporáneo o deconstructivo, se traduce a un hacer vinculante, donde no es posible desligar lo que me ocurre y afecta -aquello no material- de la materia. Esto es, en parte, lo que feministas del nuevo materialismo llaman a las relaciones encarnadas y de intra-actividad (Nardini, 2014). Siguiendo la línea de Barad (2003), el fenómeno del dibujo llega a importarnos - afectarnos- y a materializarse, cuando hacemos visible el carácter situado y la posición encarnada de quien dibuja. Esto implica, en primer lugar, autorizar al cuerpo a trazar y además dar reflexividad a dicho hacer corporal.

Si vinculamos las ideas del nuevo materialismo con la lógica derridiana, podemos concluir que aprender dibujo significa cuestionar su normativa individual para abrir sus fisuras y permitir lo relacional de dicha práctica. En este sentido, los puntos de quiebre o rupturas subyacentes a la práctica del dibujo en la formación inicial, llevan a revisar los modos en que los producimos, revisando no solo nociones de espacio, materialidad y temporalidad, sino sobre todo de intercorporeidad; donde vive y actúa el sujeto (Contreras, 2008). La materialidad del cuerpo no siempre coincide con lo físico. Lo corpóreo vincula lo tangible con lo intangible, lo que pienso, con lo que tengo, soy y proyecto ser, en un contexto de espacio, materialidad y temporalidad. Según Butler (2002), el cuerpo va más allá de lo carnal, por ello el pensamiento es parte de nuestra corporeidad. En este sentido, si promovemos al cuerpo «en situación de dibujo» permitimos subjetividad, puesto que ésta:

Se produce socialmente de manera constante y remite a la corporeidad del sujeto en todas sus dimensiones. (...) Ésta emerge en múltiples circunstancias: en medio de contingencias, modos transitorios de vida, luchas permanentes, entre el deseo, las presiones sociales y las necesidades de vivir y sobrevivir (Martínez \& Cubides 2012, p.176).

A través de estas autoras pensamos que la subjetividad promovida a lo largo del curso Dibujo Deconstructivo, no alude a una posibilidad de ser artista-docente dada, sino a una con- 
tingencia que permite nuevas formas de comprender(nos), saber y transitar (Braidotti, 2004) por el aprendizaje de las artes. Es un viaje de trayectorias que no se cierran a lo dado o establecido, sino que permite nuevas maneras de vivirnos y explorarnos. Desde aquí que lo ejercitado en el curso, tanto la experiencia de cuestionar lo que hacemos como el aprender a trazar (con) el cuerpo, se transforman en conocimientos pertinentes (Morin, 2010) que responden al enfoque posmoderno de la enseñanza de las artes (Raquimán \& Zamorano, 2017). Se pro mueven saberes contextuados porque se sitúan en lo que cada estudiante vive, le importa y afecta para aprender su vínculo de hacer con el dibujo. Este hacer, no trata entonces de un grafismo objetivo, sino de una relación con, porque aprendemos a dibujar con el cuerpo en situación de acción y reflexión. Hablamos de un trazo que no está enfocado en reproducir la realidad, sino cuestionarla desde aquello que nos acontece en el cuerpo como deseo de ser.

Por último, consideramos relevante promover más espacios e instancias de aprendizajes artísticos posmodernos en la formación inicial, que acojan a lo deconstructivo como una base epistémica que dialogue con los contenidos o prácticas a experimentar en los cursos, para generar nuevas experiencias de aprendizaje que transformen lo dado en una difracción de saberes subjetivos.

La propuesta deconstructiva que nos entregó Derrida es una base conceptual y metodológica rica para desafiar los conocimientos de la academia - o la zona de confort del profesorado-, y permitir que tanto el estudiantado como quienes enseñamos cuestionemos nuestras prácticas y saberes individuales para abrirnos a la práctica relacional del saber-hacer. 
Acaso, M. (2012). Pedagogías invisibles. El espacio del aula como discurso. Madrid: Catarata.

Atkinson, D. (2011). Art, equality and learning. Pedagogies against the State. Netherlands: Sense Publishers.

Atkinson, D. (2016). Without Criteria: Art and Learning and the Adventure of Pedagogy. The international journal of art \& design education, 36(2), 141-152.

Barad, K. (2003). Posthumanist Performativity: Toward an Understanding of How Matter Comes to Matter. Journal of Women in Culture and Society. 28(3), 801-831.

Barthes, R. (2002). Lo obvio y lo obtuso. Paidós: Barcelona.

Bazzuro, L. (2015). Cuerpo, performance, conflicto: hacia una estética del reconocimiento moral. Resonancias, 1, 1-38.

Braidotti, R. (2004). Feminismo, diferencia sexual y subjetividad nómade. Barcelona: Gedisa

Butler, J. (2002). Cuerpos que importan. Sobre los límites materiales y discursivos del “sexo". Buenos Aires: Paidós.

Butler, J. (2004). Lenguaje, poder e identidad. Madrid: Síntesis.

Burke, P.J y Jackson, S. (2007). Reconceptualising lifelong learning: feminist interventions. New York: Routledge.

Cares, C. (2017). Arte, género y discurso. Representaciones sociales en el Chile reciente. Tesis doctoral: Universidad de Barcelona.

Contreras, M.J. (2008). Práctica performativa e intercorporeidad. Sobre el contagio de los cuerpos en acción. Revista Apuntes de Teatro, 130, 148-162.

Derrida, J. (1989). La escritura y la diferencia. Barcelona: Anthropos.

Derrida, J. (1997). Cómo no hablar. Y otros textos. Barcelona: Proyecto A.

Derrida, J. (1998). De la Gramatología. México: Siglo XXI.

Derrida, J. (2005). La verdad en Pintura. Buenos Aires: Paidós.

Derrida, J. (2008). La Hospitalidad. Buenos Aires: Ediciones de la Flor.

Espinoza, V. (2017). Cerebros dóciles: pensamiento creativo y cultura visual en el sinfín del lo contemporáneo. En Ossa, Carlos. Políticas y didácticas. Estudio sobre Educación Artística, Creatividad Social y Ciudadanía en el CNCA. (pp.26-42). Santiago de Chile: Universidad de Chile.

FranCastel, P. (1990). Sociología del arte. Madrid: Alianza.

Gergen, K. (1996). Realidades y relaciones: aproximaciones a la construcción social. Barcelona: Paidós.

Gómez-Peña, G. (2005). En defensa del arte del performance. Horizontes Antropológicos, 11(24), 199-226.

González-Victoria, L.M. (2011). Artes de acción: re-significación del cuerpo y el espacio urbano. Revista nodo, 10(5), 55-72.

Martínez, M.C., Cubides, J. (2012). Acercamientos al uso de la categoría de 'subjetividad política’ en procesos investigativos. En Piedrahita, C., Díaz, Á., Vommaro, P. (Comp.) Subjetividades Políticas: desafíos y debates latinoamericanos. (pp.169190) Bogotá: Universidad Distrital Francisco José de Caldas.

Morin, E. (2010). Pensar la Complejidad. Crisis y metamorphosis. Valencia: Universitat de Valencia.

Nardini, K. (2014). Volverse otro: el pensamiento encarnado y la "materia o importancia transformadora" de la teorización del (nuevo) materialismo feminista. Artnodes, 14, 18-25. http://dx.doi.org/10.7238/a.voi14.2412

Nochlin, L. (1971). Why Have There Been no Great Women Artists. En Gornick, Vivian, Moran, Bárbara. Woman in Sexist Society: Studies in Power and Powerlessness. (pp. 480-510). New York: Basic Books.

Ojeda, A., Bailón, C. y García, C. (2014). El Dibujo como expresión del mundo interno del migrante. Ciudad de México: Universidad Iberoamericana.

Ossa, C. (2017). Políticas y didácticas. Estudio sobre Educación Artística, Creatividad Social y Ciudadanía en el CNCA. Santiago de Chile: Universidad de Chile. 
Peirce, C. (1988). El hombre, un signo (El pragmatismo de Peirce). Barcelona, Crítica.

Peretti, C. (1989). Jacques Derrida: texto y deconstrucción. Barcelona: Anthropos.

Raquiman, P. y Zamorano, M. (2017). Didáctica de las Artes Visuales, una aproximación desde sus enfoques de enseñanza. Estudios pedagógicos. [online]. 43,1, 439-456. doi.org/10.4067/S0718-07052017000100025.

Schön, D. (1992). La formación de profesionales reflexivos. Hacia un nuevo diseño de la enseñanza y el aprendizaje en las profesiones. Barcelona: Paidós.

Schön, D. (1998). El profesional Reflexivo. Cómo piensan los profesionales cuando actúan. Barcelona: Paidós.

Sullivan G. (2010). Art Practice as Research. Inquiry in Visual Arts. Londres: Sage.

Villegas I., Navarrete, C., Camhi, B., y Espinoza, D. (2017). Dibujo en Chile (1797-1991). Variaciones epistemológicas, aplicaciones profesionales. Santiago de Chile: Lom.

Warr, T. (2011). El cuerpo del artista. Barcelona: Phaidon. 
